\title{
Scientific Research and Universities as Knowledge Based Organizations
}

\author{
Marian NĂSTASE ${ }^{1}$ \\ Margareta FLORESCU ${ }^{2}$ \\ Ileana MIRCIOI (VĂLIMĂRANU) ${ }^{3}$
}

\begin{abstract}
Innovation is representing a key word in this dynamic world and the organizations strives for attracting and using the best resources for providing highest value to their stakeholders.

Knowledge based organizations are very sensitive and sensitive to society and economy developments. Sensitivity increases due to the increased awareness of complex relationships between the organization and the environment.

The universities are among the elites of these types of and the research carried out by them support them to fulfill their critical role for local and regional development. The role of the organization itself and the impact that individual and group performance have on the overall results are amplified as they prove to be great in innovation field.

It is a major shift to see the role of universities as a trigger, but also as a fortifier of major trends that are critical for society, bringing the best from scientific research, but also from educational field and providing maximum value to their stakeholders.
\end{abstract}

Keywords: scientific research, knowledge based organizations, explicit knowledge, tacit knowledge

JEL classification: I20, I25, M10

DOI: $10.24818 /$ RMCI.2018.5.451

\section{Introduction}

Innovation is one of the main elements that currently defines an organization, with a major impact on its survival and evolution.

Things have changed greatly since the time when it was only possible to improve something and to find yourself rather on the coordinates of high stability and predictability. Now, it is imperative to constantly seek the new, to connect to

\footnotetext{
${ }^{1}$ Marian Năstase, Bucharest University of Economic Studies, Email: nastasem1 @ yahoocom

${ }^{2}$ Margareta Florescu, Bucharest University of Economic Studies,

Email: margareta.florescu@ari.ase.ro

3 Ileana Mircioi (Vălimăranu) Bucharest University of Economic Studies, Email: ileanamircioi@gmail.com
} 
approaches and mechanisms that even if they were not your traditional way of being, are now proving to bring high value to the organization.

Universities are also in the process of transforming, remodeling the role they play, and taking a lead in the impact on the economic and social development of an area, of a community (Edwards, Schedlitzki, Turnbull, Gill, 2015).

When discussing sustainable development, it is difficult to imagine a consortium of local and regional actors that does not include these outstanding representatives of the education sector.

When it comes to knowledge-based organizations, universities are at the forefront of their work, thanks to the body of experts they have and who are constantly preoccupied by scientific research projects to discover and validate novelties in a very diverse range of fields (Verboncu, Corcodel, 2014).

Universities are good environments for the development of creativity, for generating many new ideas, representing a crucible in which professionalism blends harmoniously with passion and desire for creation.

However, it is important to bear in mind that beyond the creation of new ideas, their degree of applicability is important, how they generate value in practice.

Innovation can be linear or non-linear, it can be the result of long-lasting persistence, or it can be the fruit of a punctual, well thought-out and logistically supported project.

No matter how it is produced, innovation is expected to bring value to the organization, create well-being and make a major contribution to ensuring the organization's competitive position.

Innovation in organizations can have a broad field of manifestation, being present in products, services, processes or working tools. It is important for the production of ideas to be largely related to their application so that the creative effort is later accompanied by appropriate economic, social, cultural, etc. rewards.

\section{Innovation and knowledge}

Innovation and knowledge are closely connected. Organizations to survive and develop must respond quickly to changing conditions and even anticipate them.

For all of this it is necessary to have the necessary knowledge. Knowledge is an element that influences processes and performance. They are determined by the quality of the information obtained but also by the interactions with the other members of the organization (Bibu, Năstase, Gligor, 2010).

Specialists classify knowledge on different levels, depending on various criteria. Among the most relevant and to which we now grant the well-deserved place are those identified as explicit knowledge and implicit or tacit knowledge.

Explicit knowledge can be defined as those that are relatively clear, have relatively easy identification, can be encoded, stored, presented, and used in a well- 
structured manner. Explicit knowledge is frequently encountered in formal communications.

At the same time, explicit knowledge is appropriate to public presentations, can be stored as such or synthesized, can be entered in databases, and official procedures can be developed to allow access and capitalization.

Implicit or tacit knowledge as they are in literature and practice are those that have a strong personal character and are relevant in a particular context.

Implied or tacit knowledge is highly personalized and reflects the education, values, and experience in a person's field.

The tacit knowledge differs from the explicit one in that it is not formalized and depends on the one who holds it.

The form and use of silent knowledge will depend largely on the will, goodwill, inspiration and involvement of the holder. Thus, one can understand why it is considered that, unlike the first category, they are to a very limited extent under the control of managers.

Universities, as well as many other knowledge-based organizations, need specific management for these approaches, which is a distinct area of management of the organization, namely knowledge-based management.

A fundamental priority of knowledge management is the detection of these implicit or tacit knowledge, their explanation, their expression in formalized forms, likely to lead to much more storage, processing and sharing than in the original form.

In this way, a critical component of the intellectual capital of universities can be saved, collected, enriched and added to the organization's knowledge treasury, capable of fortifying the organization, enhancing innovation and achieving its educational mission, scientific research, and economic and social development.

How to use knowledge is not simple because they are part of the intangible resource category. Elements such as organization's reputation and organizational culture are areas where leaders face problems in managing dematerialized elements.

Knowledge has a diverse range of forms, from the usual ones we apply and apply in daily activities to those necessary for major decisions.

We gain knowledge based on our education, training, experience, values that we have and involves the processing of information, but also positioning and use in a well-defined environment.

It is relatively easy to observe these elements in employees' behaviors, in the ways in which they perform their activities and in the results obtained. 


\section{Universities as knowledge-based organizations}

Through permanent scientific research carried out within universities, through concerns about innovation under a broad range of issues, higher education institutions strongly affirm their role as brand representatives of knowledge-based society and economics.

It is obvious that the value of the products and services offered by an organization is ensured by the knowledge that is included there and not by the material elements.

That is why we can speak with certainty about the manifestation of knowledge-based organizations, those entities in which the prerequisites for the development and extensive and intensive use of human and intellectual capital are created.

Universities are elite entities in the category of knowledge-based organizations, a feature that can be highlighted by the strong link with the various stakeholders.

Very important and involved in the acquisition, processing and use of knowledge are teachers, students, administrative staff, partner public institutions, authorities, suppliers, partner firms, etc.

There are many partnerships that aim at obtaining and better utilizing tangible and intangible resources and turning them into products and services useful to society (Witzel, 2012).

In this competitive society, characterized by an accelerated process of globalization, it is important that universities offer researchers the opportunity to invest in professional and professional development (Dalli, 2014).

Supporting excellence research is fundamental to the field of education and it must be promoted, included in specific strategies integrated into the strategy of the institutions in which it takes place. Starting from here, a lot of other steps can be taken to translate the approaches and standards specific to excellence research into practice.

In order to achieve meaningful results at institutional and field level, there is a need for a critical mass of teaching staff, researchers to be committed to advanced scientific research.

For this, it is necessary that this expert corps develops a wide range of skills, both in its own field of interest, but increasingly cross-cutting skills, so as to achieve a synergy effect with other related fields or support.

Research in universities takes different forms, from the fundamental one to that applied, from the advanced research carried out by experts with much experience and seniority in a certain field, to the discovery of causal relations, the characterization of certain economic, physical phenomena, chemical, etc. as is the case with some early-stage researchers, doctoral students, master students or even undergraduate students (Năstase, Dobrea, Valimareanu, 2016).

It is important for the latter to plant seeds of curiosity and passion for scientific research, to discover the laws of certain phenomena, to understand them 
properly, to anticipate and even use them to obtain the best technical, economic and social results.

Scientific research in universities must be embedded in open research, accessible to all individuals and institutions interested in participating and contributing to a particular theme.

In order to facilitate the proper concentration of specialists, it is important to have a suitable organizational environment and culture to ensure that any action is properly designed and sustained (McDonald, Ross, 2000).

New researchers must be prepared to become more creative, more critical of their own and others' work in a constructive way and benefit from a high degree of autonomy, exploring more and more the boundaries of frontier research.

\section{Characteristics of research and knowledge generation in universities}

In a dynamic society, universities are determined to discover the best ways to explore and exploit their own research capabilities and gain the most value based on their knowledge.

Societal demands lead them to strongly support researchers' creativity and innovation to respond appropriately to growing demands.

Various needs in the social, economic, cultural, technological, etc. fields. stimulates the possibilities of combining, associating disciplines and thus fostering the necessary interdisciplinary approach.

There is even a responsibility that universities assume as major local and regional actor in society, as a trigger or fortification of major modernization tendencies.

In this respect, the procedures for ensuring the quality of scientific research are important, while promoting transparency in this field and ensuring equal opportunities.

The Romanian scientific research takes into account the fundamental European principles and is increasingly present and connected to what we define as the European Research Area.

An example of this is the way in which doctoral research is stimulated, which is increasingly being cited as an important source of institutional and social innovation.

That is why we pay close attention to the way in which the preoccupations for the admission, preparation and graduation of the doctoral cycle are manifested in universities (Lockamy, 2004).

The $\mathrm{PhD}$ is further linked in various forms to the career management of the person enrolling in such a study program, and is strongly correlated with its orientation to scientific research activities, regardless of whether the individual remains in the academic, research or active business or public environment.

We also see a major change in how research institutions interact with different stakeholders. Connections are personalized, there are specific requests, and research results are increasingly focused on well-defined targets. Market 
orientation means a very good knowledge of it, and research results address those interests and needs that it needs (Nonaka,1991).

If for some time it could be noticed that many organizations used zero-sum strategies, with one winner and one or more losers, this is now rare.

Knowledge-based organizations, even if they were in earlier times in competition, trying to erode each other's markets and competitive positions, have now understood that they need to move towards other approaches that will provide them with the necessary premises for success. That is why knowledge-based organizations build strategic alliances and develop other forms of collaboration in which to achieve common goals (Green 2007).

It is obvious that we are witnessing the diminution of the life cycle of products and services at a rapid pace of moral wear and tear of knowledge, which forces organizations not to regard themselves as adversaries to similar organizations but to seek new ways of working, rather in strong consortia and putting together a series of resources to achieve better results than if they acted alone.

Leaders in universities, though concerned with providing an adequate material base, technical endowment that is needed for research, and fundamental teaching processes for higher education institutions, have understood that in order to be or to position itself in a competitive manner, the emphasis should be on human capital, on obtaining, preparing, motivating and using it in good conditions.

The success of universities is increasingly linked to the integration of human and intellectual capital into an institutional strategy that allows for continued modernization and facilitation of interdependence between these two key areas for any knowledge-based organization.

Acknowledgement: The article is one of the results of the project CNFISFDI-2018-0582 entitled "Supporting excellent research within the Academy of Economic Studies in Bucharest in the context of the principles of sustainable development and open research" (ORFEUS).

\section{References}

Bibu, N., Năstase, M. and Gligor, D.C., 2010. The perception over corporate social responsibility in Romania. Review of International Comparative Management, 11(5), pp. 764-778.

Dalli, Mehmet, 2014. The university students' time management skills in terms of their academic life satisfaction and academic achievement levels. In Educational Research and reviews. Vol. 9(20), pp.1090-1096.

Edwards, G., Schedlitzki, D., Turnbull, S., Gill, R. (2015), "Exploring power assumptions in the leadership and management debate", Leadership \& Organization Development Journal, Vol. 36, Issue 3, pp. 328-343.

Green M. (2007), Change Management Masterclass - A Step by Step Guide to Succesful Change Management, Kogan Page Limited, UK, p. 83. 
Lockamy III, A. and McCormack, K. Linking SCOR planning practices to supply chain performance, International Journal of Operations \& Production Management. Vol.24, Num.12, 2004, pp. 1192-1218.

McDonald, Ross A. (2000), "Reframing Management Education: A Humanist Context for Teaching in Business and Society", Interchange, Vol. 41/4, pp. 385-401, Kluwer Academic Publishers, Netherland.

Năstase, M., Dobrea, C., Valimareanu, (Mircioi) I., (2016), Promoting the Entrepreneurial Competencies for School Leadership Development, Review of International Comparative Management, Volume 17, Issue 1, March.

Nonaka, I. (1991), "The Knowledge-Creating Company," Harvard Business Review, Vol. 69, Issue 6, pp. 96 - 104.

Verboncu, I., Corcodel, S.-F. (2014), "Managerial Performance - Factors of Influence", Review of International Comparative Management, Vol. 15, Issue 3, pp. 273-283.

Witzel, M., (2012), A History of Management Thought, USA: Routledge. 